\title{
PELATIHAN DAN PENDAMPINGAN PENGISIAN KONTEN KELAS VIRTUAL BERBASIS WEB BLOG
}

\section{TRAINING AND ASSISTANCE OF WEB-BASED VIRTUAL CLASS CONTENT FILLING}

\author{
${ }^{1)}$ Wa Ode Lusianai, ${ }^{2)}$ La Surimi, ${ }^{3)}$ Ikrima Nurfikria, ${ }^{4)}$ Aryuni Salpiana Jabar, ${ }^{5}$ Siti \\ Hairani Idrus, ${ }^{6}$ Hasriany Amin \\ ${ }^{1,6)}$ Komunikasi, ${ }^{2)}$ Teknik Informatika, ${ }^{3)}$ Jurnalistik, ${ }^{4)}$ Kesejahteraan Sosial, ${ }^{5)}$ Administrasi Bisnis \\ ${ }^{1,3,4,5,6)}$ Fakultas Ilmu Sosial dan Ilmu Politik, ${ }^{2}$ Fakultas Teknik \\ ${ }^{1,2,3,4,5,6)}$ Universitas Halu Oleo
}

Email: ${ }^{1)}$ lusianaiwaode@uho.ac.id, ${ }^{2)}$ lasurimi@uho.ac.id, ${ }^{3)}$ ikrima80@gmail.com, ${ }^{4)}$ aryuni@uho.ac.id,

${ }^{5}$ hairani.idrus@gmail.com, ${ }^{6} \underline{\text { hasriany.amin@uho.ac.id }}$

\begin{abstract}
ABSTRAK
Perkembangan teknologi informasi telah diadopsi di berbagai bidang tidak terkecuali dunia pendidikan dalam bentuk e-learning. Universitas Halu Oleo (UHO) mendorong terlaksananya sistem pembelajaran berbasis online. Berbagai kegiatan pelatihan dan bimbingan teknis (bimtek) e-learning dilakukan namun tidak memberikan dampak yang signifikan. Kondisi ini terjadi dikarenakan keterbatasan waktu serta tidak adanya pendampingan pasca pelatihan dan bimtek. Dengan menggunakan metode pendekatan kemitraan melalui pelatihan dan pendampingan, kegiatan ini bermitra dengan perwakilan dosen dari setiap jurusan/program studi lingkup Fisip UHO. Kurangnya minat dan kemampuan dalam menggunakan kelas virtual baik dari segi pengelolaan dan desain tampilan kelas virtual hingga pengisian konten menjadi masalah prioritas yang dialami mitra. Hasil kegiatan menunjukkan perubahan pengetahuan dan keterampilan dalam menggunakan web blog yang terkoneksi dengan blog dosen UHO di lecture.uho.ac.id. Dosen yang mengikuti kegiatan pengabdian ini telah memanfaatkan kelas virtual blog dosen dalam beberapa mata kuliah baik sebagai sarana berbagi materi maupun tugas kuliah. Melalui pengabdian ini, telah ada sembilan web blog yang bisa menjadi blog dosen percontohan dari jurusan/Prodi lingkup Fisip dan bisa digunakan untuk menunjang akreditasi. Tidak hanya itu, tim pengabdian juga menyediakan ruang komunikasi bagi mitra dan tim untuk memastikan kelas virtual terus aktif dan produktif sebagai bentuk kegiatan pendampingan melalui grup WhatsApp.
\end{abstract}

Kata kunci: E-learning; Kelas virtual; Konten; Web blog

\section{ABSTRACT}

The development of information technology has been adopted in various fields, including education in the form of e-learning. Halu Oleo University (UHO) encourages the implementation of an online-based learning system, so that various training activities, e-learning training, and technical guidance are carried out; yet do not have a significant impact. This condition occurs due to time constraints and the absence of post-training assistance and technical guidance. With a partnership approach method through training and mentoring, this activity is carried out in partnership with representatives lecturer from each department /study program in the scope of the Faculty of Social and Political Sciences UHO. Lack of interest and ability to use virtual class in management, design of the virtual class display, and filling content becomes a priority problem experienced by partners. The results of the activity show changes in knowledge and skills in using web blogs connected to the UHO lecturer blog at lecture.uho.ac.id. The lecturers who participated in this service had utilized the virtual blog class of lecturers in several subjects, both as a means of sharing material and assignments. Through this activity, there have been nine web blogs that can become a pilot lecturer blog from the departments/ study programs within the Faculty of Social Sciences and can be used to support 
accreditation. Furthermore, the community service team also provides communication space for partners and teams to ensure that virtual classes continue to be active and productive as a form of mentoring activities through the WhatsApp group.

Keywords: E-learning; Virtual class; Content; Web blog

Submitted : 27 November 2019 Revision : 8 September 2020 Accepted : 18 September 2020

\section{PENDAHULUAN}

Perguruan tinggi merupakan lembaga pendidikan tinggi yang memiliki tugas dan fungsi melaksanakan proses pembelajaran yang optimal. Hal ini menjadi upaya menciptakan lulusan yang berkualifikasi standar nasional. Pelaksanaan pembelajaran dalam rangka melaksanakan tugas Tri Darma perguruan tinggi yang harus memperhatikan kualitas dosen dalam merencanakan, melakukan, dan menilai proses Tri Darma perguruan tinggi (Liantoni dkk, 2019). Untuk mewujudkan hal tersebut, Universitas Halu Oleo (UHO) telah mengembangkan media pembelajaran dengan memanfaatkan teknologi informasi yang dikenal dengan $e$ learning dengan menyelenggaran berbagai pelatihan maupun bimtek tentang google classroom, blog dosen dan yang paling terakhir di bulan Mei 2019 adalah bimtek pendidikan jarak jauh dengan menggunakan aplikasi moodle (egreen.uho.ac.id). Peserta kegiatan diikuti oleh perwakilan beberapa dosen dari setiap fakultas, tidak terkecuali fakultas ilmu sosial dan ilmu politik (Fisip).

Penggunaan media pembelajaran online di Fisip masih sangat sedikit, sehingga berdampak pada proses akreditasi program studi (Prodi). Hal ini seperti yang terjadi pada tahun 2019, ketika beberapa Prodi lingkup Fisip mendapat kunjungan untuk proses akreditasi dan reakreditasi. Salah satu hal yang menjadi perhatian tim assessor adalah pembelajaran online atau e-learning yang digunakan oleh dosen di Prodi tersebut. Di sinilah masalah itu muncul, kurangnya dosen memanfaatkan media pembejaran serta kurangnya kemampuan dalam menggunakan $e$ learning. Kondisi ini seharusnya tidak terjadi, karena selalu ada perwakilan dosen Fisip yang diikutikan dalam pelatihan maupun bimtek yang diselenggarakan oleh UHO tentang e-learning. Namun, upaya yang dilakukan univeritas dalam mendorong penggunaan e-learning tidak ditunjang dengan pendampingan pasca pelatihan sehingga mitra merasa kesulitan dalam penerapannya.

Salah satu media pembelajaran online yang digunakan di UHO adalah web blog yang terkoneksi dengan blog dosen UHO di lecture.uho.ac.id. Berbeda dengan google classroom, web blog lebih publik sifatnya dan dapat diakses bebas melalui internet. Blog memberikan sebuah peluang agar kegiatan belajar lebih menarik dan interaktif. Melalui blog, sumber-sumber materi yang relevan dapat dipublikasikan sehingga bisa diakses oleh mahasiswa. Dengan demikian kesulitan mahasiswa dalam mengumpulkan sumber-sumber informasi yang dibutuhkan dalam proses pembelajaran dapat diatasi (Wahyudi, 2014). Untuk itu, dibutuhkan kreatifitas dan kemampuan dosen Fisip UHO menyajikan konten dan desain tampilan yang menarik. Hal ini akan turut menggambarkan kualitas mitra di tengah keterbukaan akses informasi di dunia pendidikan.

Menulis di web blog layaknya menulis di sebuah media, bagaimana media tersebut mampu menarik mata pembacanya 
melalui konten yang dikonstruksi. Sesuai dengan tujuan kegiatan jurnalistik dalam rangka mempengaruhi khalayak, unsur keindahan sajian produknya sangat diutamakan. Indah dalam artian dapat diminati dan dinikmati (Suhandang, 2004). Kelas virtual web blog pun demikian, pengisian konten menjadi sesuatu yang harus diperhatikan agar menarik minat pembaca sehingga tidak hanya dikunjungi oleh mahasiswa dan dosen UHO tetapi lebih jauh dapat diakses dan dirujuk oleh mahasiswa dan dosen di luar UHO. Untuk itulah, kegiatan pengabdian ini, tidak berhenti di pelatihan namun sifatnya berkelanjutan melalui pendampingan kelas virtual dengan dibentuk media komunikasi sharing antara mitra dan tim pengusul melalui grup WhatsApp.

Pelatihan dan pendampingan pengisian konten kelas virtual menjadi penting dilakukan, sehingga kegiatan pengabdian ini bersifat berkelanjutan dalam membantu mewujudkan terciptanya generasi cerdas dengan memanfaatan media komunikasi berbasis teknologi. Kegiatan pelatihan ini ditujukan pada dosen perwakilan dari Prodi/jurusan lingkup Fisip dan terus didampingi serta dibuatkan media komunikasi interaktif antara mitra dan tim pelaksana sebagai wujud pendampingan demi mewujudkan visi dan misi Fisip serta menunjang proses reakreditas dan akreditasi Prodi. Pendampingan mitra menjadi penekanan dalam kegiatan pengabdian ini, sehingga tidak ada mitra yang terlibat yang tidak bisa mengisi dan memanfaatkan media pembelajaran onlinenya. Langkah ini diambil sebagai solusi dalam melihat permasalahan yang dialami mitra dan urgensi dari e-learning bagi perguruan tinggi.

Pada akhirnya pelatihan dan pendampingan pengisian konten kelas virtual menjadi langkah awal berkembangnya model pembelajaran $e$ learning dalam mendukung program pemerintah di dunia pendidikan serta mengatasi kesenjangan pendidikan. Jika memungkinkan, ini menjadi dasar bagi Fisip untuk dikenal lebih luas karena sifat media pembelajarannya yang bisa diakses secara umum.

\section{METODE}

Dengan menggunakan metode kemitraan, pengabdian ini bermitra dengan dosen Fisip UHO dari jurusan/Prodi lingkup Fisip yakni komunikasi, jurnalistik, perpustakaan, politik, pemerintahan, sosiologi, kesejahteraan sosial, administrasi publik, dan adminisrasi bisnis. Kegiatan pengabdian ini menempatkan mitra sebagai obyek sekaligus subyek dengan harapan adanya keaktifan dan keterbukaan dalam menyampaikan masalah dan kondisi yang diharapkan dari permasalahan. Mitra akan diberikan ruang untuk sharing tentang faktor penyebab atau motif dari permasalahan yang terjadi kemudian akan diedukasi apa yang seharusnya dilakukan untuk meningkatkan dan menghidupkan kelas virtualnya web blog.

Untuk mewujudkan hal tersebut, maka ditempuh langkah-langkah sebagai berikut :

1. Persiapan: (a) memastikan kesiapan dan kesediaan mitra (kontak dengan pimpinan Fisip); dan (b) Memastikan lokasi kegiatan yang fleksibel dan nyaman bagi mitra.

2. Pelatihan: (a) menyiapkan tema yang berhubungan dengan konten kelas virtual; (b) menentukan waktu dan tempat pelaksanaan; (c) Menyiapkan narasumber yang berkompeten dibidang ini yakni perwakilan dari IT dan Jurnalistik/Komunikasi; mengundang peserta yang terdiri dari dosen perwakilan jurusan/Prodi lingkup Fisip UHO, keterwakilan pimpinan Fakultas. dan perwakilan media online; (e) melakukan tanya jawab antara peserta dengan narasumber; dan (f) praktek pengelolaan tema/tampilan dan pengisian konten kelas virtual web blog. 
3. Pendampingan: (a) membentuk obrolan grup WhatsApp (WA) yang akan dikoneksikan dengan web blog masingmasing sebagai media sharing antara mitra dan tim pengusul; dan (b) memastikan komunikasi grup berjalan maksimal sehingga proses komunikasi bisa berlangsung dimana saja dan kapan saja.

4. Evaluasi: (a) rancangan evaluasi melalui pengelolaan kelas virtual web blog dengan tampilan menarik untuk mengukur kemampuan mitra dalam mengoperasikan kelas virtualnya; dan (b) rancangan evaluasi melalui pengisian konten kelas virtual web blog untuk melihat pemahaman dan kemampuan dalam kreatifitas konten kelas virtual mitra.

Pada akhirnya, kegiatan ini selain menghasilkan kelas virtual melalui web blog mitra dari perwakilan setiap jurusan/Prodi lingkup Fisip, juga terus berlanjut melalui grup obloran WA sebagai bentuk pendampingan dan evaluasi.

\section{HASIL DAN PEMBAHASAN}

Pelatihan e-learning berbasis web blog terkoneksi dengan blog dosen UHO di lecture.uho.ac.id merupakan kegiatan yang berawal dari permasalahan mitra dalam menggunakan blog dosen yang disediakan oleh institusi. Gambar 1 menunjukkan penyampian materi oleh tim.

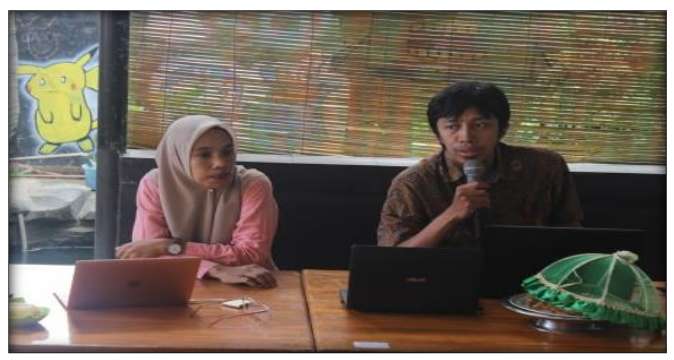

Gambar 1. Penyampaian Materi oleh La Surimi, S.Si., M.Cs
Gambar 1 merupakan Pemateri, La Surimi, S.Si., M.T dan dibantu oleh tim, Wa Ode Lusianai, menyampikan materi dengan metode ceramah dan praktek dengan menggunakan media infokus dalam penyampaiannya. Untuk memberikan pengenalan dan pengetahuan mitra akan pemanfaatan blog dosen dalam pembelajaran dan juga penunjang akreditasi dilakukan dengan metode ceramah. Selanjutnya, mitra praktek menggunakan blog dosen dengan mendesain tampilan dan mengisi konten.

$$
\text { Jauh sebelum pelatihan }
$$

berlangsung, tim memastikan peserta yang ikut dalam kegiatan harus mempunyai email institusi sebagai syarat dibuatnya akun blog dosen UHO. Untuk itu bagi yang belum memiliki email institusi maka tim mendampingi mitra untuk mendapatkan email institusi melalui UPT TIK UHO. Setelah semua mitra memiliki email intitusi, mitra kemudian dipandu untuk melakukan registrasi akun blog dosen. Kegiatan ini semua berlangsung dengan memanfaatkan media komunikasi WA group yang dibuat sebelum kegiatan pelatihan. Berikut link WA yang dijasikan sebagai media pendampingan,

(https://chat.whatsapp.com/HXSFqUzVd8 65HMPYWm9KfZ).

Memulai pembuatan grup sebelum kegiatan pelatihan berlangsung juga ditujukan untuk memastikan mitra telah mendapatkan halaman site, sebagai tindak lanjut dari proses registrasi blog dosen melalui lecture.uho.ac.id. Melalui grup WA ini, mitra dapat menyampaikan berbagai keluhan dalam mendapatkan halaman site grup dosen UHO sehingga pada saat pelatihan, mitra hanya fokus pada cara mengisi dan mendesain konten

Pelatihan blog dosen diikuti oleh sembilan dosen perwakilan jurusan/Prodi lingkup Fisip yakni komunikasi, jurnalistik, perpustakaan, politik, pemerintahan, kesejahteraan sosial, sosiologi, administrasi publik, administrasi bisnis. Halaman site blog dosen wajib 
dimiliki oleh setiap peserta sebelum kegiatan pelatihan berlangsung. Berikut tahapan mendapatkan halaman site blog dosen UHO yang dilakukan oleh mitra :

1. Memiliki email institusi seperti lusianaiwaode@uho.ac.id. Untuk mendapatkan email institusi, dosen menghubungi pustik UHO. Namun melalui kegiatan ini, mitra yang tergabung dalam grup WA pengabdian cukum mengirim nama lengkap dan NIDN melalui grup WA untuk diteruskan kepada pengelola blog dosen UHO yakni UPT TIK.

2. Registrasi blog dosen UHO melalui lecture.uho.ac.id. Dalam proses registrasi, mitra akan mengisi username dan email institusi. Setelah itu, akan masuk di email institusi pemberitahuan untuk mengklik verifikasi data. Ketika pertama kali membuka email institusi, pesan masuk ini biasanya masuk di spam bukan di inbox. Setelah proses verifikasi selesai akan muncul username dan password. Mitra kemudian mengirimkan username, nama lengkap dan NIDN ke dalam grup WA yang kemudian tim mengusulkan pembuatan halaman site kepada pustik UHO sehingga ada halaman site masingmasing mitra seperti lecture.uho.ac.id/waodelusianai. Berikut daftar halaman site blog dosen UHO dari mitra :
Tabel 1. Daftar Halaman Site Blog Dosen yang Mengikuti Pelatihan

\begin{tabular}{|c|c|c|c|}
\hline No & $\begin{array}{l}\text { Jurusan } / \mathrm{P} \\
\text { rodi }\end{array}$ & Nama Dosen & $\begin{array}{c}\text { Halaman Site } \\
\text { Blog Dosen }\end{array}$ \\
\hline 1 & $\begin{array}{l}\text { Komunik } \\
\text { asi }\end{array}$ & $\begin{array}{l}\text { La Ode } \\
\text { Herman } \\
\text { Halika }\end{array}$ & $\begin{array}{l}\text { Lecture.uho.ac.id/ } \\
\text { hermanhalika/ }\end{array}$ \\
\hline 2 & $\begin{array}{l}\text { Jurnalisti } \\
\mathrm{k}\end{array}$ & $\begin{array}{l}\text { M. Djufri } \\
\text { Rachim }\end{array}$ & $\begin{array}{l}\text { Lecture.uho.ac.id/ } \\
\text { djufrirachim/ }\end{array}$ \\
\hline 3 & $\begin{array}{l}\text { Perpustak } \\
\text { aan }\end{array}$ & Muliati & $\begin{array}{l}\text { Lecture.uho.ac.id/ } \\
\text { muliatiperpustakaa } \\
\text { n/ }\end{array}$ \\
\hline 4 & Politik & $\begin{array}{l}\text { Dodi } \\
\text { Santoso }\end{array}$ & $\begin{array}{l}\text { Lecture.uho.ac.id/ } \\
\text { dodisantoso/ }\end{array}$ \\
\hline 5 & $\begin{array}{l}\text { Pemerint } \\
\text { ahan }\end{array}$ & $\begin{array}{l}\text { Faturachman } \\
\text { Alputra S. }\end{array}$ & $\begin{array}{l}\text { Lecture.uho.ac.id/f } \\
\text { atur/ }\end{array}$ \\
\hline 6 & Sosiologi & $\begin{array}{l}\text { Rety Reka } \\
\text { Merlins }\end{array}$ & $\begin{array}{l}\text { Lecture.uho.ac.id/r } \\
\text { etyrekamerlins/ }\end{array}$ \\
\hline 7 & $\begin{array}{l}\text { Kesejahte } \\
\text { raan } \\
\text { Sosial }\end{array}$ & Sarmadan & $\begin{array}{l}\text { Lecture.uho.ac.id/s } \\
\text { armadan/ }\end{array}$ \\
\hline 8 & $\begin{array}{l}\text { Administ } \\
\text { rasi } \\
\text { Publik } \\
\end{array}$ & $\begin{array}{ll}\text { La } & \text { Ode } \\
\text { Aslim } & \end{array}$ & $\begin{array}{l}\text { Lecture.uho.ac.id/l } \\
\text { aodeaslim/ }\end{array}$ \\
\hline 9 & $\begin{array}{l}\text { Administ } \\
\text { rasi } \\
\text { Bisnis }\end{array}$ & Rosikah & $\begin{array}{l}\text { Lecture.uho.ac.id/r } \\
\text { osikah }\end{array}$ \\
\hline
\end{tabular}

Tabel 1 merupakan halaman site blog dosen yang dibuat sebelum kegiatan pelatihan melalui grup WA sehingga di hari pelaksanaan pelatihan, peserta fokus pada pengisian dan desain tampilan blog dosen. Halaman site inilah sebagai pintu masuk dosen untuk mulai mengisi blog dosennya sesuai dengan kebutuhan dengan dengan tidak terlepas dari kegiatan trihdarma perguruan tinggi yakni pendidikan dan pengajaran, penelitian, pengabdian.

Pelaksanaan pelatihan difokuskan pada kegiatan desain tampilan dan cara mengisi konten blog dosen. Berikut tahapan desain dan pengisian konten blog dosen :

1. Masuk di halaman site misalnya lecture.uho.ac.id/waodelusianai. Untuk masuk sebagai admin, maka dapat ditambahkan dashboard misalnya lecture.uho.ac.id/waodelusianai/dashbo ard/, maka akan muncul tampilan pada gambar 2 . 


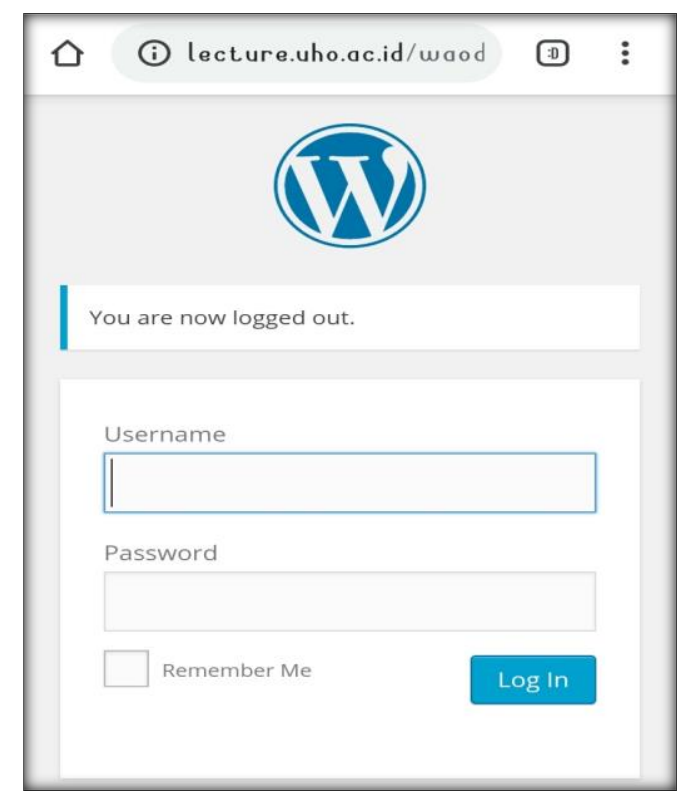

Gambar 2. Tampilan Log In Blog Dosen

Masukkan username dan password yang ada pada saat verifikasi di email institusi ada kolom di gambar 2. Password dapat berubah sesuai keinginan untuk lebih mudah diingat sedangkan username tidak bisa berubah.

2. Mengganti password. Password dapat diganti sesuai keinginan dengan melalui menu users $\rightarrow$ your profile $\rightarrow$ new password $\rightarrow$ update profile.

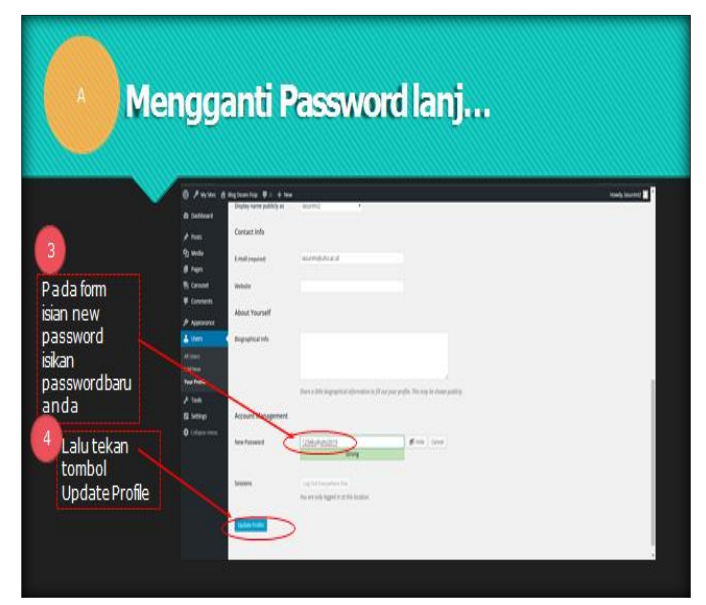

Gambar 3. Tahapan Mengganti Passwoord Blog Dosen
Pada menu dashboard, seperti gambar 3 , ada menu user dan sub menu your profile. Pada jendela bawah your profile, klik general password untuk mengganti password blog dosen. Pada form isian new password, diisi dengan password baru kemudian klik update profile.

3. Mengganti tema. Tema merupakan tampilan awal ketika blog dibuka (Gambar 4). Langkah mengganti tema dapat dilakukan dengan membuka menu dashboard $\rightarrow$ appearance $\rightarrow$ themes $\rightarrow$ activate tema yang dipilih.

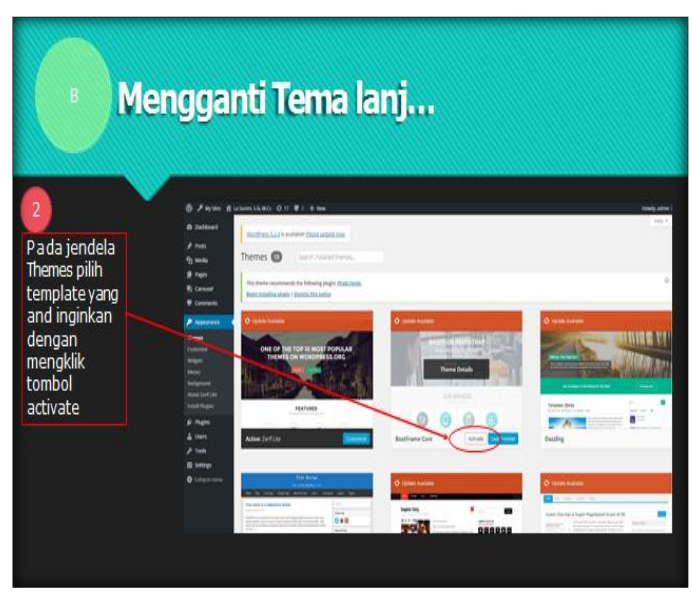

Gambar 4. Tahapan Mengganti Tema Blog Dosen

Memilih tema tertentu akan berhubungan dengan tampilan pada menu utama blog. Untuk itu, sebelum memutuskan untuk memilih tema apa yang akan digunakan dalam blog dosen (activate), admin dapat mengklik live preview untuk melihat perubahan tampilan pada menu utama. Jika tema suka dengan tema tersebut maka langsung di activate.

4. Membuat menu. Pilihan menu yang akan muncul pada sitebar blog dosen sebaiknya menggambarkan aktivitas tridharma (Gambar 5). Berikut tahapan dalam membuat menu; dashboard $\rightarrow$ appearance $\rightarrow$ menus $\rightarrow$ nama kategori menu $\rightarrow$ create menu. 

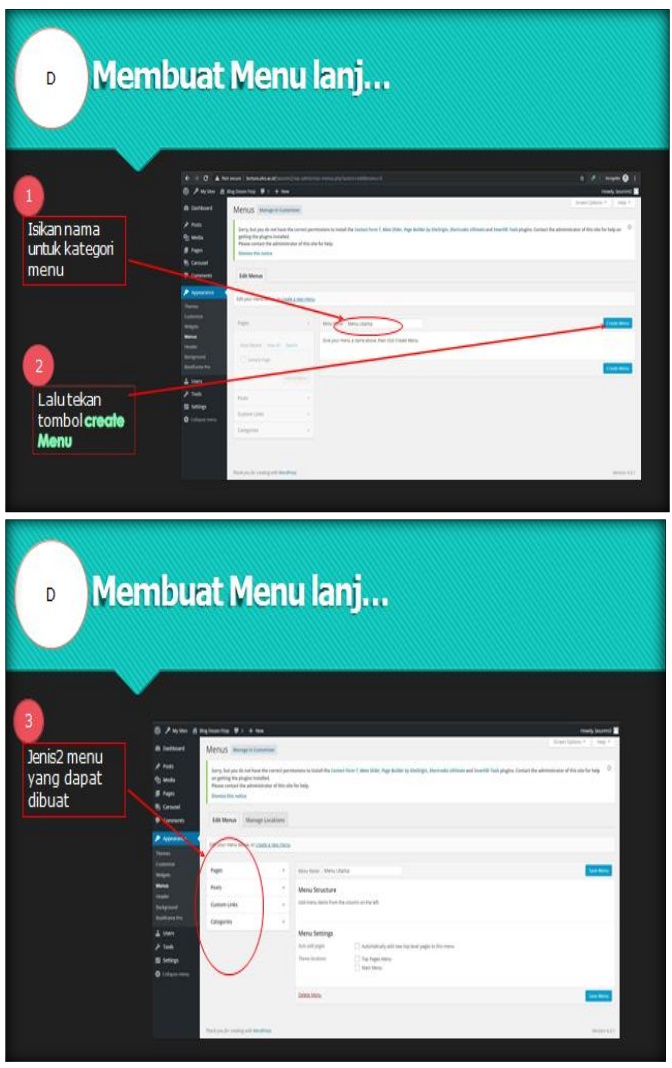

Gambar 5. Membuat Menu Blog Dosen

Dalam membuat menu, ada empat jenis menu yang dapat dibuat yakni pages, posts, costum links, dan categories. Tahapan membuat menu jenis page adalah: dashboard $\rightarrow$ pages $\rightarrow$ add new $\rightarrow$ judul page $\rightarrow$ isi page $\rightarrow$ publish $\rightarrow$ appearance $\rightarrow$ menus $\rightarrow$ pages $\rightarrow$ view all $\rightarrow$ centang bagian page yang akan dijadikan menu $\rightarrow$ add to menu.

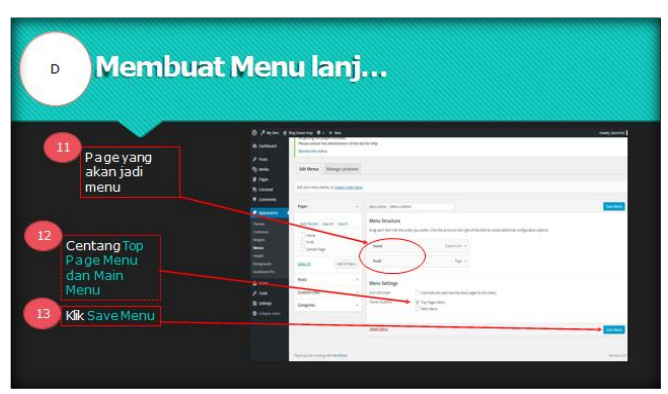

Gambar 6. Membuat Menu Jenis Pages
Menu jenis pages dibuat dengan masuk melalui dashboard, kemudian menu pages (Gambar 6). Untuk memulai membuat page, klik add page. Masukkan judul page pada bagian ini. Judul page inilah yang akan muncul di sitebar blog dosen. Untuk itu, judul page sebaiknya menggambarkan tridharma atau aktivitas seorang dosen, seperti pendidikan, pengajaran, penelitian, pengabdian, publikasi, dan lain-lain. Ketika judul page sudah dipublish, maka selanjutkan kembali ke menu appearance, menus, kemudian pages. Judul page yang telah dibuat akan muncul pada menu pages di appearance dan belum muncul di menu sitebar blog dosen. Untuk muncul di sitebar, klik view all, kemudian centang judul page dan add to menu page yang telah dipilih tersebut. Page inilah yang akan dimunculkan di sitebar blog dosen. Setelah memilih page untuk dijadikan menu, selanjutkan centang top page menu dan main menu, kemudian save menu.

5. Memposting, merupakan point penting dalam penggunaan blog dosen, dimana melalui fasilitas ini dapat berbagi informasi dengan siapapun yang mengakses. Informasi yang bisa dibagikan sangat beragam, mulai dari materi pembelajaran dalam berbagai bentuk (word, pdf, ppt, video) hingga informasi lain yang berkaitan dengan tridharma (pendidikan dan pengajaran, penelitian, pengabdian). Berikut tahapan dalam membuat postingan di blog dosen; dashboard $\rightarrow$ post $\rightarrow$ new post $\rightarrow$ judul post $\rightarrow$ isi post $\rightarrow$ publish. 

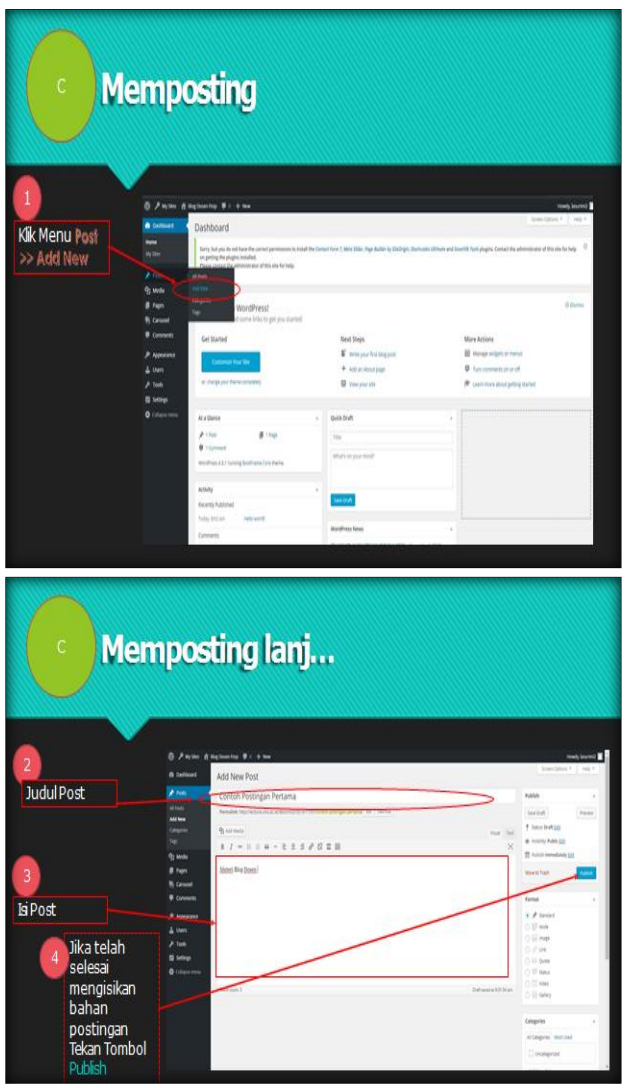

Gambar 7. Tahapan Membuat Postingan di Blog Dosen

Pada menu post ada pilihan all post, new post, categories, dan tags, maka yang dipilih adalah new post (gambar 7). Langkah selanjutnya, pada menu new post, ketikkan judul artikel yang akan dipublikasi. Buatlah judul artikel yang mengandung informasi yang lengkap dan tidak ambigu, dan sebaiknya mengandung unsur subyek dan predikat. Pada bagian isi post, informasi yang tersaji harus lengkap yang dapat dilengkapi dengan tambahan foto, dokumen (pdf, ppt, word). Selain itu, bagian isi juga dapat dibagikan video yang dapat bersumber dari youtube ataupun video bukan dari youtube.

Postingan video yang bersumber dari youtube dapat dibuat dengan cara mengambil kode embed konten youtube tersebut (gambar 8). Dengan menggunakan kode embed menjadikan pengunjung blog hanya menonton langsung video di dalam blog tanpa terhubung dengan youtube. Tahapan memasukkan kode embed untuk konten video di blog melalui; youtube $\rightarrow$ pilih konten sesuai dengan artikel $\rightarrow$ share $\rightarrow$ copy $\rightarrow$ paste dalam isi post.

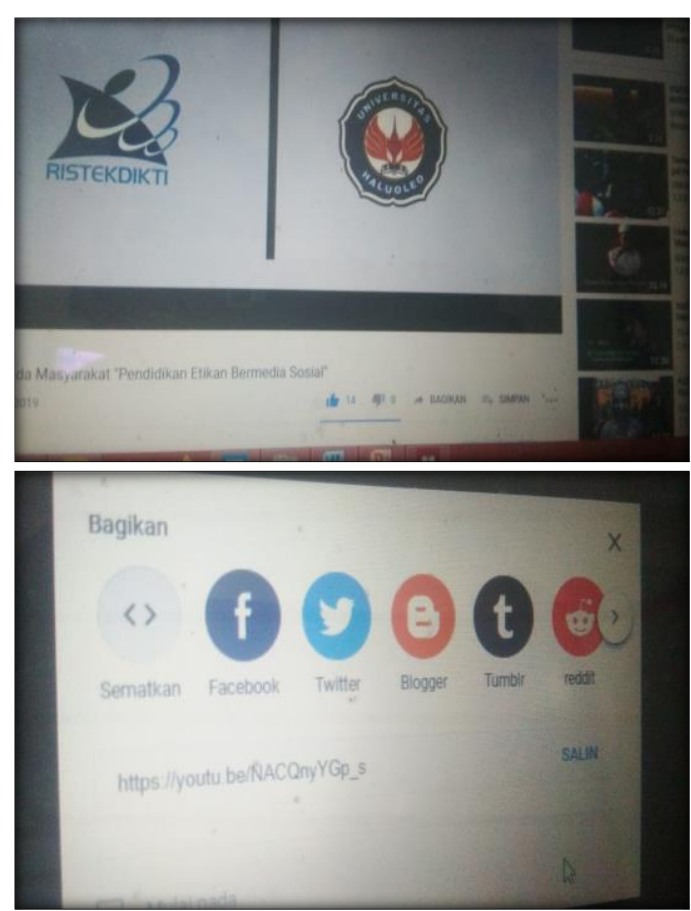

Gambar 8. Cara Memasukkan Kode Embed Video

Membuat postingan melalui blog yang terkoneksi dengan blog dosen institusi harus memperhatikan kualitas tulisan yang mampu menggambarkan aktivitas trihdarma. Media ini dapat diakses oleh semua kalangan sehingga memungkinkan dosen dan mahasiswa lain di luar insitusi dapat mengakses informasi disini. Untuk itu, melalui pelatihan ini, mitra ditekankan dalam mengisi konten media pembelajaran melalui blog dosen agar mengadopsi unsur penulisan sebuah berita yang harus mengandung $5 \mathrm{~W}+1 \mathrm{H}$ (Sugiharto, 2019). Artinya bahwa produk jurnalistik dalam bentuk berita dikonstruksi baik dari segi judul maupun isinya semenarik mungkin agar mau dibaca, didengar dan dinonton oleh masyarakat. Demikian halnya dengan konten blog 
dosen, harus mampu dikontruksi seindah mungkin sehingga menarik minat untuk dikunjungi.

Selain desain tampilan blog dosen, pengisian konten agar menarik bagi pengunjung menjadi fokus utama kegiatan pengabdian ini. Sebagai media massa yang bebas diakses oleh masyarakat, maka blog dosen harus mampu menarik minat pembacanya untuk bisa berkunjung. Sebuah media massa membutuhkan kontribusi dari pembaca atau konsumennya. Minimal pembaca berkontribusi dalam mengkonsumsi atau membaca hasil sajian awak redaksi atau bagian periklanan (Sugiharto, 2019). Untuk blog dosen, bagian redaksi atau periklanan dipegang sendiri oleh dosen yang bersangkutan. Untuk itu, sebagai pengguna dan sekaligus pengelola blog dosen pribadi yang terkoneksi dengan institusi, tidak cukup dengan mengikuti pelatihanpelatihan dan bimtek seperti ini, tetapi juga dibutuhkan kesadaran untuk belajar secara mandiri dengan memanfaatkan mesin pencari google.

Hal positif dalam pelatihan ini, mitra sangat antusias mengikutinya, dengan mengisi dan mendesain tampilan blog dosen yang dimiliki. Sebagian besar mitra baru menggunakan blog sebagi media berkomunikasi dengan mahasiswa dalam proses pembelajaran. Untuk memanfaatkan blog sebagai media pembelajaran interaktif yaitu dengan cara mengisi menu yang ada di blog dengan materi-materi pelajaran,tugas perkuliahan dengan format text, gambar, audio maupun video, sehingga terjadi interaksi yang baik antara dosen dengan mahasiswa (Wahyudi, 2014). Untuk itu, tim secara cermat dan penuh semangat mendampingi mitra dalam menggunakan blog dosen, dimulai dari merubah password, tema, mengisi menu, sampai mengisi konten sebagai bagian penting dalam pengelolaan website sebagai media komunikasi pembelajaran online.

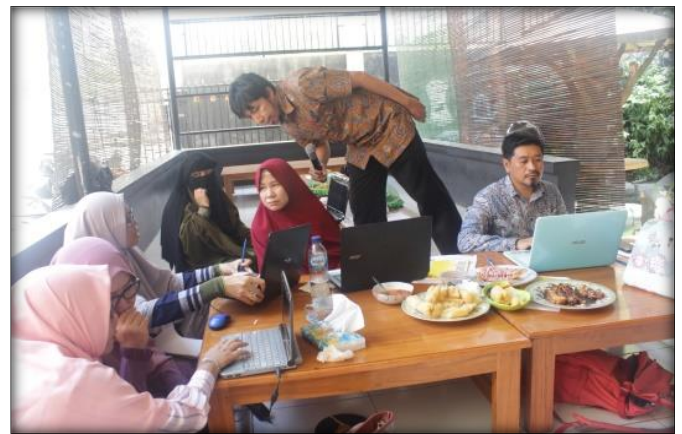

Gambar 9. Suasana Pelatihan Blog Dosen

Gambar 9 menunjukkan antusiasme mitra dalam belajar menggunakan dan mengelola blog dosen. Pemateri nampak melihat secara langsung kerja mitra dalam praktek mendesain dan mengisi blog dosen sehingga mitra mendapatkan manfaat yang banyak dari satu kegiatan pelatihan. Manfaat tersebut adalah mitra mampu dan telah menggunakan blog dosen yang terkoneksi dengan blog dosen UHO di lecture.uho.ac.id, mitra mampu dan telah menyambungkan media google classroom dengan blog dosen pribadi yang bisa diakses oleh mahasiswa, dosen dan masyarakat umum.

Hasil kegiatan pelatihan ini adalah adanya blog dosen dari setiap peserta yang menjadi mitra dengan pemahaman dan kemampuan mitra dalam mengelola secara mandiri blog dosennya. Pada gambar 10 merupakan sampel tampilan blog dosen mitra yang dibuat pada saat pelatihan.

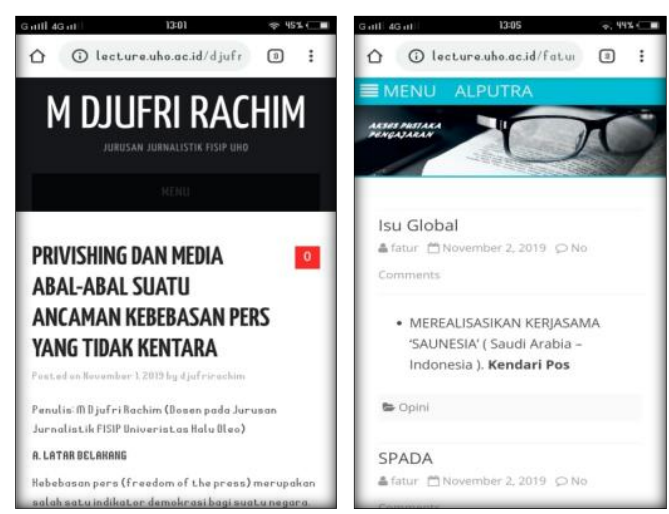

Gambar 10. Tampilan Blog Dosen Mitra 
Gambar 10 merupakan tampilan visual blog dosen hasil dari kegiatan pelatihan ini. Gambar tersebut menunjukan kemampuan mitra dalam memahami dan menggunakan blog dosen sebagai media komunikasi online untuk berbagi informasi seputar aktivitas tridharma dosen. Selain itu, melalui blog dosen ini, mitra berbagi informasi yang berkaitan dengan bidang ilmu dan program studi.

Hasil evaluasi kegiatan pelatihan dengan melihat kemampuan mitra dalam mengelola blog dosennya dalam hal mendesain dan mengisi konten kelas virtualnya sesuai dengan kebutuhan tridharma. Selain itu, kemampuan mitra dalam hal kemandirian dalam mengelola blog dosen secara mandiri setelah kegiatan pelatihan juga menjadi indikator keberhasilan program pelatihan ini. Dengan adanya kemampuan mitra dalam mengetahui dan menggunakan media pembelajaran online berbasis blog dosen, maka kegiatan pengabdian pengisian konten kelas virtual berbasis web blog selesai. Namun demikian, ada kegiatan pendampingan yang terus berjalan selamanya melalui grup WA yang telah dibuat sebelum kegiatan pelatihan dilaksanakan. Grup WA ini beranggotakan sembilan dosen dari perwakilan setiap jurusan/Prodi dan juga tim pengabdian. Pendampingan ini ditujukan untuk mengatasi dan memberikan soluasi atas permasalahan mitra terkait blog dosen.

\section{SIMPULAN}

Pengabdian pengisian konten kelas virtual melalui media komunikasi online blog dosen yang diselenggaran selama satu hari telah memberikan dampak yang signifikan dalam hal pemanfaatan dan penggunaan media pembelajaran online. Hal ini tergambar dari adanya kelas online blog dosen setiap peserta yang telah didesain dan diisi sesuai dengan kebutuhan dosen dalam tridharmanya.

\section{UCAPAN TERIMA KASIH}

Tim mengucapkan terima kasih kepada Universitas Halu Oleo melalui LPPM atas bantuan dana hibah pengabdian tahun 2019, dan juga kepada mitra, pimpinan Fakultas Ilmu Sosial dan Ilmu Politik yang sangat mendukung kegiatan pengabdian ini.

\section{DAFTAR PUSTAKA}

Liantoni, F., Arief, R., Rozi, N.F., \& Sodik, A. (2019). Peningkatan proses pembelajaran melalui pelatihan kuliah online bagi dosen. Jurnal Pengabdian Pada Masyarakat, 4(1), 105-110.

https://doi.org/10.30653/002.201941. 65

Sugiharto, R. T. (2019). Panduan Menjadi Jurnalis Profesional. Yogyakarta: Araska.

Suhandang, K. (2004). Pengantar jurnalistik seputar organisasi, produk, \& kode etik. Bandung: Nuansa Cendekia.

Wahyudi, N. (2014). Pemanfaatan blog sebagai media pembelajaran interaktif. Jurnal Study Islam Panca Wahana, 9(1), 84. 